\title{
IFN- $\gamma$ induces senescence-like characteristics in mouse bone marrow mesenchymal stem cells
}

\author{
Zhou Xin Yang ${ }^{A-D, F}$, Gen Xiang Mao ${ }^{A-C, F}$, Jing Zhang ${ }^{B, E, F}$, Xiao Lin Wen ${ }^{B, C}$, Bing Bing Jia ${ }^{B, C}$, \\ Yi Zhong Bao ${ }^{B}$, Xiao Ling LV ${ }^{C}$, Ya Zhen Wang ${ }^{B}$, Guo Fu Wang ${ }^{A, C, E, F}$ \\ Zhejiang Provincial Key Lab of Geriatrics, Zhejiang Hospital, Hangzhou, China \\ A - research concept and design; B - collection and/or assembly of data; C - data analysis and interpretation; \\ $D$ - writing the article; $E$ - critical revision of the article; $F$ - final approval of article
}

Address for correspondence

Guo Fu Wang

E-mail: 1090983005@qq.com

\section{Funding sources}

none declared

\section{Acknowledgements}

The study was supported by the open funds of the Zhejiang Provincial Key Lab of Geriatrics, research funds of the Zhejiang Hospital (2013YJ006), major national science and technology projects (2013ZX09303005), the National Natural Science Foundation of China (31201040, 31301139), the Science Technology Department of Zhejiang Province (2012(24005), the Health Bureau of Zhejiang Province (2013KYA003 \& 2013ZDA002), and the Zhejiang Provincial Administration of Traditional Chinese Medicine (2012-XK-A04).

\section{Conflict of interest}

none declared

Received on August 07, 2015

Revised on October 09, 2015

Accepted on January 19, 2016

\begin{abstract}
Background. Mesenchymal stem cells (MSC) are considered promising in tissue repair and regeneration medicine due to their proliferation and differentiation ability. Many properties of MSC are affected by cytokines, and IFN- $\gamma$ has been shown to regulate MSC in many aspects. Senescence affects the proliferation, differentiation and cytokine secretion of MSC.

Objectives. To investigate the effects of IFN- $\gamma$ on the senescence-associated properties of MSC.

Material and methods. The MSC used in our study were isolated from the bone marrow (BM) of mice. Cell vitalities were measured by CCK8. The phenotypes and ROS of mBM-MSC were analyzed by flow cytometry. Cellular senescence was detected using SA- $\beta$-gal stains. IL- 6 and CXCL1 secretions were measured by ELISA.

Results. mBM-MSC can differentiated into osteocytes and adipocytes. They expressed CD29, CD106, and SCa-1, and did not express CD31, CD45 or FLK1. Our study showed that the cell vitalities of mBM-MSC were significantly reduced after IFN- $y$ treatment for 5 days, and the cell numbers were obviously lower after IFN- $y$ treatment for 5,10 or 15 days. The IFN- $\gamma$ group increased SA- $\beta$-gal-positive cells and reactive oxygen species (ROS) significantly after 15 days of IFN- $y$ treatment. Moreover, IL-6 and CXCL1 secretions were upregulated by IFN- - .

Conclusions. Our study shows IFN- $\gamma$ can induce senescence-like characteristics in mBM-MSC, suggesting a novel target for anti-aging therapy.
\end{abstract}

Key words: IFN- $\gamma$, senescence, mesenchymal stem cells

DOI

10.17219/acem/61431

\section{Copyright}

Copyright by Author(s)

This is an article distributed under the terms of the

Creative Commons Attribution Non-Commercial License

(http://creativecommons.org/licenses/by-nc-nd/4.0/) 
Mesenchymal stem cells (MSC) have been isolated from many kinds of tissues, and MSC derived from bone marrow have been studied the most. MSC proliferate in culture flasks quickly in vitro and differentiate into cells of the mesoderm, such as osteoblasts, adipocytes, chondrocytes, tendon and muscle cells under certain conditions. ${ }^{1}$ Further research has also shown that MSC can differentiate into cells of the ectoderm and endoderm. ${ }^{2}$ Thus, MSC is supposed to be promising in tissue repair and regeneration medicine.

MSC undergoes genomic mutation after long term in vitro culture, and becomes senescent. ${ }^{3}$ The senescence of MSC in vitro has been shown to be a continuous process, and senescence progress starts in the early passages. ${ }^{4}$ Additionally, MSC can be induced to premature senescence. Oxidative stress was one of the major inducers of premature senescence of MSC. ${ }^{5}$ Like other cells, the proliferations of MSC were reduced by cellular senescence, and senescent MSC were stained by SA- $\beta$-gal. ${ }^{6}$ The osteogenic and adipogenic differentiation potential of MSC were reduced by cellular senescence. ${ }^{7}$ Moreover, the cytokine secretion of MSC was affected. ${ }^{8}$ Thus, senescence affects many characteristics of MSC, and influences their in vivo function.

MSC are able to regulate the immune response and change the cytokine secretion of immune cells. ${ }^{9}$ IFN- $\gamma$ is one of the major cytokines for Th1 response, which is critical for cellular immunity. MSC can suppress IFN- $\gamma$ production of $\mathrm{CD}^{+}, \mathrm{CD}^{+}$and $\mathrm{NK}$ cells, and IFN- $\gamma$ changes many properties of MSC. ${ }^{9}$ IFN- $\gamma$ induces MSC-expressed IDO1, which inhibits the proliferation of immune cells, and MSC itself. ${ }^{10,11}$ IFN- $\gamma$ also inhibits the osteogenic and adipogenic differentiation potential of human and mouse MSC. ${ }^{11}$ CD106 and CD54 expressions on MSC could be up-regulated by IFN- $\gamma$, and they are important for the hematopoietic support and immune modulation abilities of MSC. ${ }^{12}$ Moreover, IFN- $\gamma$ is also an inducer of the chemokine secretion of MSC. ${ }^{13}$ IFN- $\gamma$ has been shown to induce senescence of many kinds of cells, including cancer cells, melanocytes and endothelial cells. ${ }^{14-16}$ IFN- $\gamma$ reduces proliferation of these cells while inducing ROS and DNA damage signaling. However, research on the effects of IFN- $\gamma$ on stem cell senescence is limited.

In our study, we studied the effect of IFN- $\gamma$ on mBMMSC senescence-associated properties. We discovered that IFN- $\gamma$ could suppress the proliferations of mBM-MSC and induce senescence-like characteristics of mBM-MSC. Additionally, IFN- $\gamma$ regulated the senescence-associated cytokine IL- 6 and CXCL1 production of mBM-MSC.

\section{Material and methods}

\section{Generation of mouse bone marrow mesenchymal stem cells}

Bone marrow cells were collected from 6-10 week old C57BL/ 6 mice by flushing femurs and tibias with $2 \mathrm{~mL}$ needles. The cells were seeded in a flask at a density of $10^{6} / \mathrm{cm}^{2}$. The basic culture medium for the isolation of MSC was the MesenCult ${ }^{\mathrm{TM}}$ Proliferation Kit (Stemcell Technologies, Vancouver, Canada) or Dulbecco's modified Eagle's medium containing 10\% FBS. Three days later, non-adherent cells were removed from the culture. The cells were cultured at $37^{\circ} \mathrm{C}$ in an atmosphere maintaining $5 \% \mathrm{CO}_{2}$ and passed at $80 \%$ confluence. Cells of passage 7 to passage 12 were used. The experimental procedures used in this study had been approved by the ethics committee within Zhejiang Hospital.

\section{Flow cytometric analysis}

The phenotypes of mBM-MSC were analyzed using the following antibodies: PE-Cy7-conjugated-CD31; PEconjugated-CD29, CD45, CD106; APC-conjugated-FLK1 and Sca-1. Non-specific isotype-matched antibodies served as controls. All of the antibodies were purchased from eBioscience (San Diego, USA). Cells were analyzed using flow cytometry in a Beckman Coulter FC 500, and the data was analyzed using the FlowJo software (FlowJo LLC, Ashland, USA).

\section{Osteogenic and adipogenic differentiation}

mBM-MSC were plated in 24-well plates at a density of 3000 cells $/ \mathrm{cm}^{2}$. The medium was changed with specific induction medium $24 \mathrm{~h}$ later. For osteogenic and adipogenic differentiation induction, kits were purchased from Cyagen Biosciences Inc. (Santa Clara, USA). After 3 weeks of induction, the cells were stained using Alizarin red $\mathrm{S}$ or oil red $\mathrm{O}$ solution.

\section{Proliferation assay}

For the cell vitality assay, mBM-MSC were seeded $10^{3}$ per well in $0.1 \mathrm{~mL}$ of DMEM with 10\% FBS in 6-well plates. In the IFN- $\gamma$ stimulated group, IFN- $\gamma(1 \mathrm{ng} / \mathrm{mL}$ or $10 \mathrm{ng} / \mathrm{mL}$ ) was added. The cells were analyzed using a Cell Counting Kit-8 (Beyotime Biotechnology, Shanghai, China). For cumulative population doublings (CPD) assay, mBM-MSC were seeded $5 \times 10^{4}$ per well in $2 \mathrm{~mL}$ of DMEM with $10 \%$ FBS in 6-well plates, and the medium changed after adherence to the flask. In the IFN- $\gamma$ stimulated group, IFN- $\gamma(10 \mathrm{ng} / \mathrm{mL})$ was added. Cells were detached in the $5^{\text {th }}, 10^{\text {th }}$ and $15^{\text {th }}$ days. The cells were counted and CPD were calculated. 


\section{Senescence-associated beta-galactosidase (SA- $\beta$-gal) staining}

mBM-MSC stimulated by IFN- $\gamma(10 \mathrm{ng} / \mathrm{mL})$ for 15 days were studied. The control group was mBM-MSC cultured without IFN- $\gamma$ for 15 days. The culture mediums were discarded, and cells were washed with phosphate buffered saline. SA- $\beta$-gal staining was performed using a SA- $\beta$-gal staining kit (Genmed Scientifics Inc., Plymouth, USA) following the supplier's instructions. The percentages of SA$\beta$-gal positive cells out of the total number of cells were counted.

\section{Reactive oxygen species detection}

mBM-MSC stimulated by IFN- $\gamma(10 \mathrm{ng} / \mathrm{mL})$ for 15 days were studied. Culture mediums were discarded, and the cells were washed with phosphate-buffered saline. The cells were incubated with $10 \mu \mathrm{M}$ H2DCFDA (SigmaAldrich, St. Louis, USA) for $30 \mathrm{~min}$ and ROS were detected by flow cytometry.

\section{ELISA}

mBM-MSC stimulated by IFN- $\gamma(10 \mathrm{ng} / \mathrm{mL})$ for 15 days were isolated and seeded $3 \times 10^{4}$ per well in $0.5 \mathrm{~mL}$ of DMEM with $10 \%$ FBS in 24 -well plates. The IFN- $\gamma$ group was treated with $10 \mathrm{ng} / \mathrm{mL}$. Cell-free supernatants were collected $24 \mathrm{~h}$ later and kept in a refrigerator at $-80^{\circ} \mathrm{C}$. IL- 6 and CXCL1 ELISA kits were purchased from eBioscience (San Diego, USA), which were used following the supplier's instructions.

\section{Statistical analysis}

The data was analyzed for statistical significance using GraphPad Prism software (San Diego, USA). The data was presented as mean \pm SEM. Student's unpaired t-test and ANOVA with Bonferroni post-hoc test were used to determine significance. $\mathrm{P}<0.05$ was considered to be statistically significant.

\section{Results}

\section{Isolation of mouse bone marrow mesenchymal stem cells}

After seeding, the bone marrow cells adhered to the flask, and proliferated quickly in the culture. Unlike in humans, several kinds of cells with different appearances could proliferate in the first few passages. Flow cytometry analysis showed that there were large amounts of $\mathrm{CD} 45^{+}$cells. The percentage of $\mathrm{CD} 45^{+}$cells became very
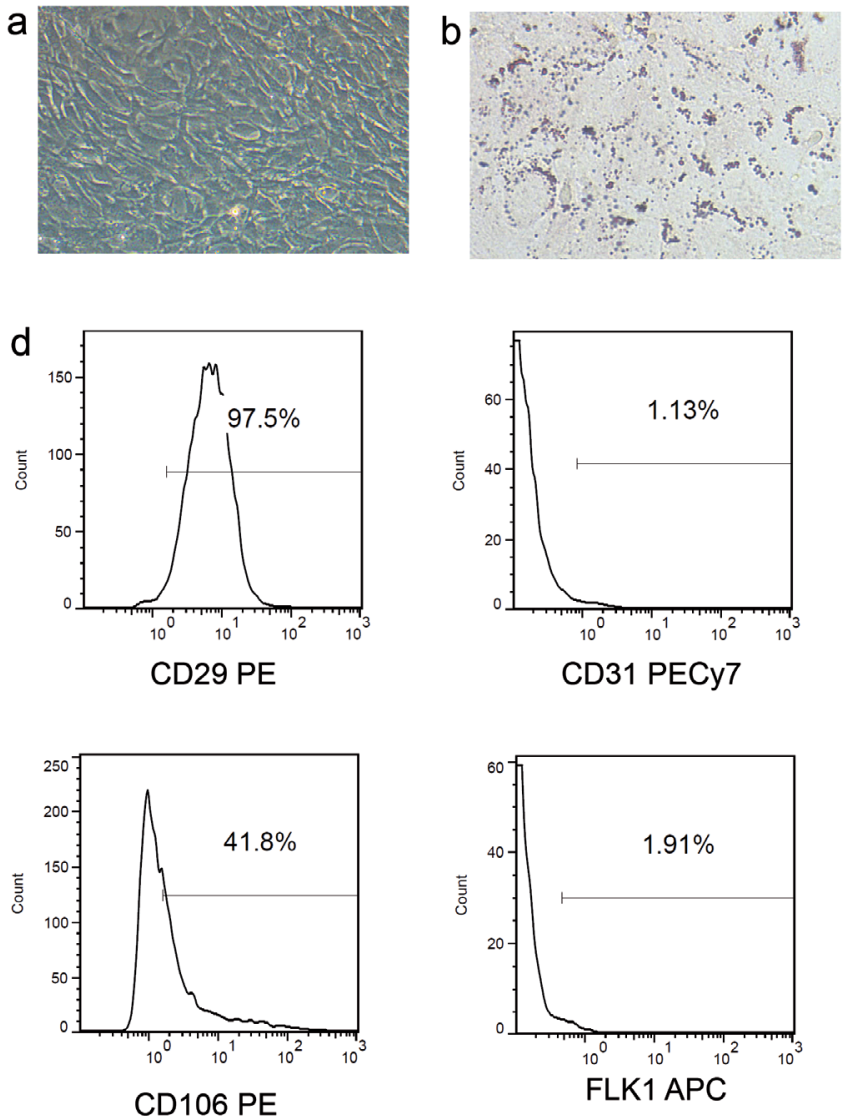

FLK1 APC
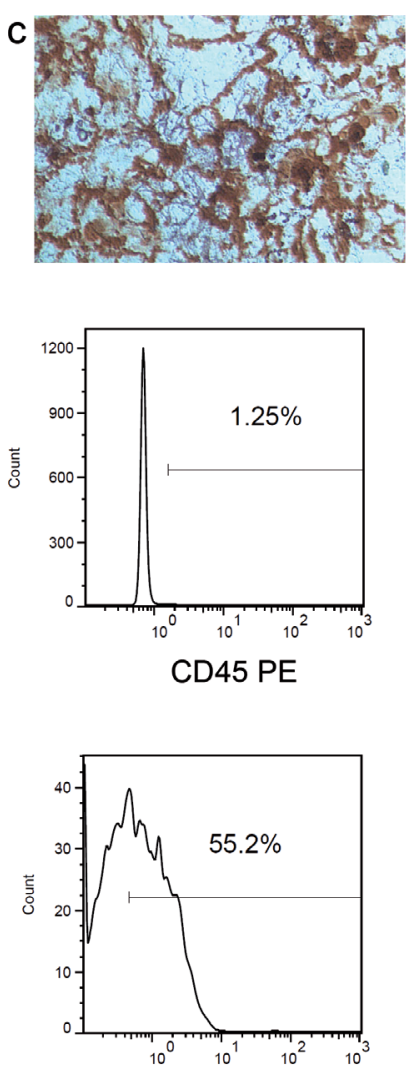

Sca-1 APC
Fig. 1. Isolation of mBM-MSC. Cells of passage 7 to passage 12 were used. mBM-MSC were tested from 3 C57BL/6 mice and shown. Images for morphology and differentiation of mBM-MSC were taken by LEICA DMIL LED microscope

Fig. 1a. Morphology of mBM-MSC

Fig. 1b. Adipogenic differentiation potential of mBM-MSC. Cells were stained using oil red $\mathrm{O}$

Fig. 1c. Osteogenic differentiation potential of mBM-MSC. Cells were stained using Alizarin red S

Fig. 1d. Phenotypes of mBMMSC. Cells were analyzed by flow cytometry in a Beckman Coulter FC 500 cytometer, and the data was analyzed using the FlowJo software 
low after passage 6 and the cells become uniform (Fig. 1a). Thus, the cells of passage 7 to passage 12 were used for the experiments. We tested their differentiation abilities and phenotypes. They differentiated into osteocytes and adipocytes under certain differentiation-inducing conditions (Figs. 1b, c). They expressed CD29, CD106, and Sca1, while not expressing CD31, CD45 and FLK1 (Fig. 1d).

\section{IFN- $\gamma$ inhibit proliferation of mBM-MSC}

We tested the effects of IFN- $\gamma$ on mBM-MSC proliferation. One $\mathrm{ng} / \mathrm{mL}$ and $10 \mathrm{ng} / \mathrm{mL}$ IFN- $\gamma$ were used to stimulate mBM-MSC. After 120 h, CCK 8 were used to test cell vitalities. The cell vitalities were significantly reduced by either concentration of IFN- $\gamma$ (Fig. $2 \mathrm{a}, \mathrm{p}<0.001$ ), and the OD in the $10 \mathrm{ng} / \mathrm{mL}$ IFN- $\gamma$ group were lower than the OD in the $1 \mathrm{ng} / \mathrm{mL}$ IFN- $\gamma$ group. Because of that, we used $10 \mathrm{ng} / \mathrm{mL}$ IFN- $\gamma$ to treat mBM-MSC for 15 days and tested its effect on mBM-MSC proliferation. In the IFN- $\gamma$ group, proliferation of mBM-MSC was reduced significantly after 5,10 or 15 days' treatment (Fig. 2 b, $\mathrm{p}<0.05$ after 5 days, $\mathrm{p}<0.001$ after 10 and 15 days).

\section{IFN- $\gamma$ induce mBM-MSC SA- $\beta$-gal and ROS}

As the proliferation potentials of $\mathrm{mBM}$-MSC were reduced by IFN- $\gamma$, we supposed that IFN- $\gamma$ might be an inducer of mBM-MSC senescence. Therefore, we stained the SA- $\beta$-gal on the mBM-MSC. The percentages of SA$\beta$-gal positive cells in the IFN- $\gamma$ group were almost 3 times that of the control group (Figs. $3 a$ and $b, p<0.01$ ). ROS were suggested to be important for premature senescence. As expected, ROS were up-regulated in mBM-MSC after 15 days of IFN- $\gamma$ treatment (Fig. 4).

\section{IFN- $\gamma$ up-regulated IL-6 and CXCL1 production of $\mathrm{mBM}-\mathrm{MSC}$}

We tested the IL- 6 and CXCL1 production after 15 days of IFN- $\gamma$ treatment. IL-6 secretions were significantly up-regulated after 15 days of IFN- $\gamma$ treatment (Fig. 5a, $5.21 \pm 0.27 \mathrm{pg} / \mathrm{mL}$ in the control group vs $49.97 \pm 2.86 \mathrm{pg} / \mathrm{mL}$ in the IFN- $\gamma$ group, $\mathrm{p}<0.001)$. Additionally, the CXCL1 secretions were up-regulated significantly (Fig. 5b, $17.61 \pm 1.00 \mathrm{pg} / \mathrm{mL}$ in the control group vs $40.92 \pm 2.64 \mathrm{pg} / \mathrm{mL}$ in the IFN- $\gamma$ group, $\mathrm{p}<0.01$ ). a

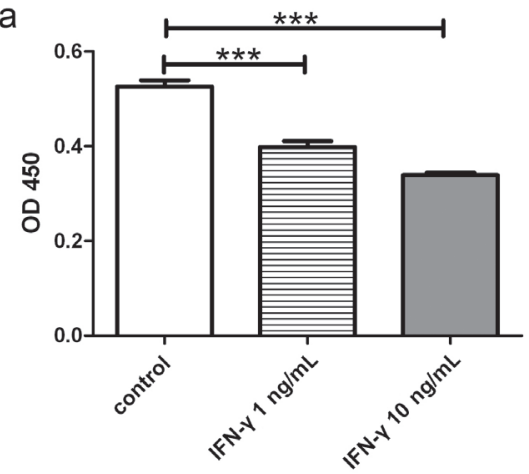

b

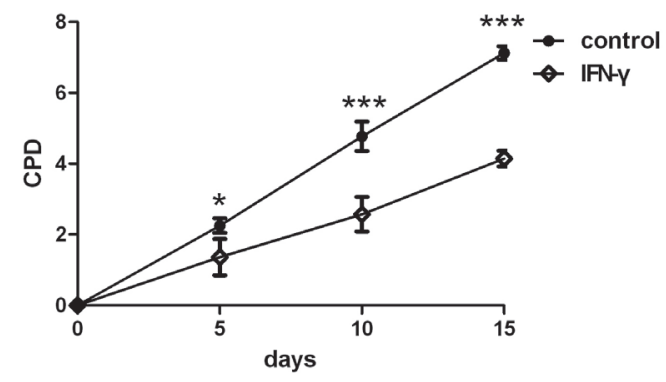

Fig. 2. IFN- $\gamma$ inhibited proliferation of mBM-MSC

Fig. 2a. mBM-MSC were cultured with IFN- $\gamma(1 \mathrm{ng} / \mathrm{mL}$ or $10 \mathrm{ng} / \mathrm{mL})$ for $120 \mathrm{~h}$ and cell vitalities were detected by CCK8. The data represents a single experiment, each performed in triplicate $\left({ }^{* *} p<0.001\right)$

Fig. 2b. mBM-MSC were cultured with IFN- $\gamma(10 \mathrm{ng} / \mathrm{mL})$ for 15 days. The cells were processed and counted. CPD were calculated. The data represents a single experiment, each performed in triplicate $\left({ }^{*} p<0.05,{ }^{* * *} p<0.001\right)$ a

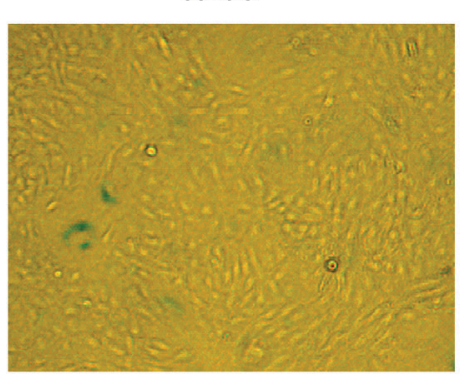

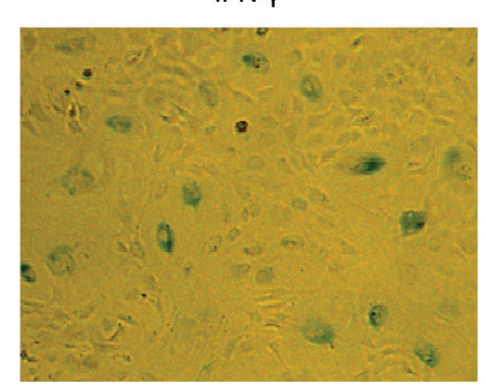

b

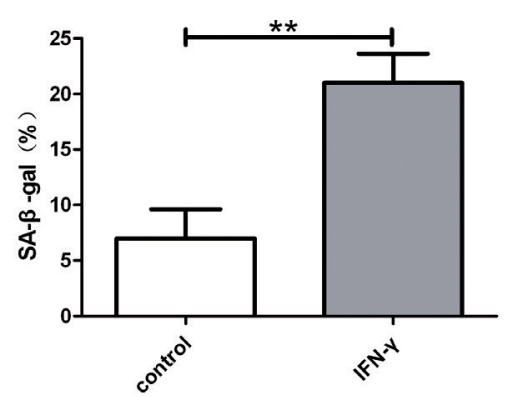

Fig. 3. IFN- $\gamma$ induced SA- $\beta$-gal of mBM-MSC. mBM-MSC were cultured with IFN- $\gamma(10 \mathrm{ng} / \mathrm{mL})$ for 15 days

Fig. 2a. Cells of none-confluent state were washed with PBS, fixed with $4 \%$ formaldehyde and stained in a staining solution containing $1 \mathrm{mg} / \mathrm{mL} 5$-bromo-4chloro-3-indolyl- $\beta$-D-galactoside for $16 \mathrm{~h}$. Images were taken by LEICA DMIL LED microscope

Fig. 2b. Percentages of SA- $\beta$-gal positive cells out of the total number of cells were counted. The data represents a single experiment, each performed in triplicate $\left.{ }^{* *} p<0.01\right)$ 


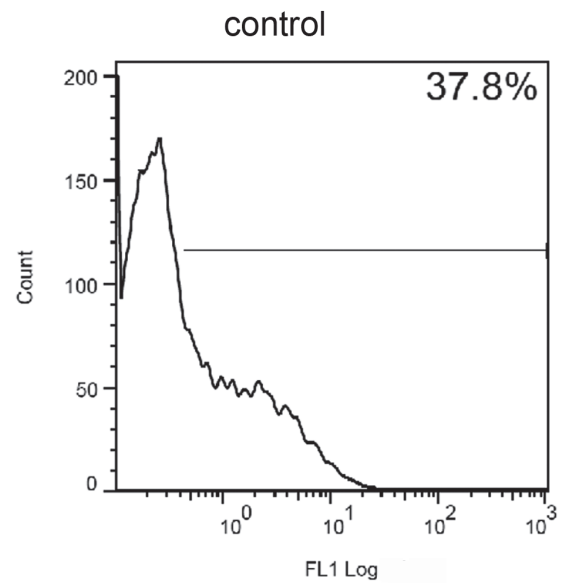

a

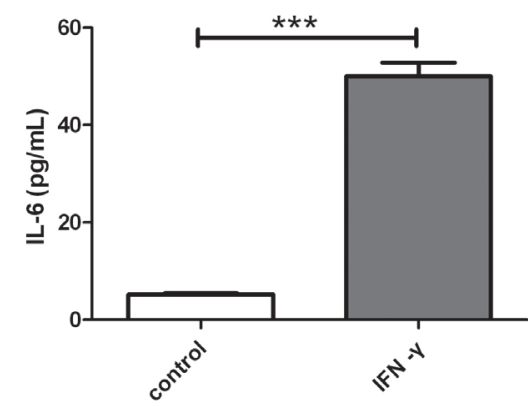

IFN-Y

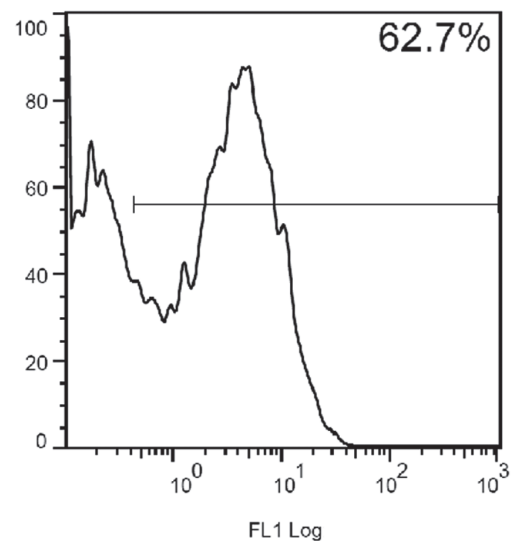

b

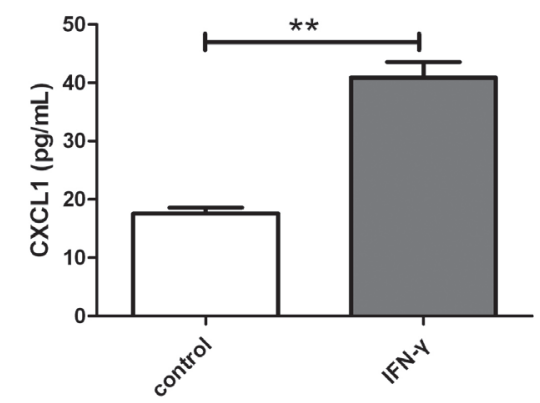

Fig. 4. IFN- $\gamma$ induced ROS of $\mathrm{mBM}$ MSC. mBM-MSC were cultured with IFN-y $(10 \mathrm{ng} / \mathrm{mL})$ for 15 days. ROS of mBM-MSC from the untreated group and IFN- $\gamma$ group were detected by flow cytometry. The data represents a single experiment, each performed in triplicate

\section{Discussion}

Mesenchymal stem cells are populations of stem cells possessing great proliferation potential, while senescence limits its proliferate and function. Many studies have been done on replicative senescence of MSC before our research, and our data shows that the Th1 cytokine IFN- $\gamma$ accelerates senescence-like characteristics in mBM-MSC.

Consistent with other research, IFN- $\gamma$ reduced the proliferations of mBM-MSC in our study. A long-term in vitro culture with IFN- $\gamma$ induced SA- $\beta$-gal expression of MSC, suggesting the role of IFN- $\gamma$ on the dysfunctions of many organs in aging. Studies have shown that MSC could regulate the immune response, especially inhibiting the Th1 response. ${ }^{10,17,18}$ It has been suggested that the IFN- $\gamma$ produced by $\mathrm{T} / \mathrm{B} / \mathrm{NK}$ cells could activate the immune modulation effects of MSC, and MSC inhibits the proliferation and IFN- $\gamma$ production of these cells. ${ }^{10,18}$ Our data suggests high concentrations of IFN- $\gamma$ could be an inducer of MSC senescence, and inflammatory cytokines could cause damage to MSC. It has been suggested that IFN- $\gamma$ is an inducer of reactive oxygen species in endothelial cells, hepatocytes and melanocytes. ${ }^{15,16,19}$ In our study, reactive oxygen species rose after 15 days of IFN- $\gamma$ treatment. ROS are thought to be one of the major factors that cause cellular DNA damage, and subsequent senescence. ${ }^{20}$ Thus, we suppose that IFN- $\gamma$ induced ROS could be the cause of senescence of mBM-MSC.
Cellular senescence induces many cytokines, which was suggested to be the senescence-associated secretory phenotype (SASP). ${ }^{21}$ SASP is controlled by NF- $\mathrm{kB}$, and could exacerbate cellular senescence. ${ }^{22}$ IL- 6 and CXCL1 were important cytokines in the SASP of mice. ${ }^{23}$ The up-regulation of IL- 6 and CXCL1 by IFN- $\gamma$ were consistent with the inducing senescence of MSC by IFN- $\gamma$. IL- 6 is an important cytokine that regulates immune cells like B cells, Th17 cells and monocytes, so the effects of increasing IL-6 production of MSC might affect the immune responses. ${ }^{24}$ Additionally, CXCL1 is related to immune response and angiogenesis. ${ }^{25,26}$ Thus, 15 days of IFN- $\gamma$ treatment might change the immune modulation and supportive effect of mBM-MSC. Other cytokines might also be influenced, and further studies are needed.

In summary, we have discovered that IFN- $\gamma$ could induce senescence-like characteristics of mBM-MSC, suggesting a novel target for anti-aging therapy. Further studies will focus on the change of differentiation, immune modulation and supportive potential of MSC, and the mechanisms of IFN- $\gamma$ induced MSC senescence.

\section{References}

1. Caplan Al. Mesenchymal stem cells. J Orthop Res. 1991;9:641-650.

2. Jiang Y, Jahagirdar BN, Reinhardt RL, et al. Pluripotency of mesenchymal stem cells derived from adult marrow. Nature. 2002;418:41-49. 
3. Wang Y, Zhang Z, Chi Y, et al. Long-term cultured mesenchymal stem cells frequently develop genomic mutations but do not undergo malignant transformation. Cell Death Dis. 2013;4:e950.

4. Wagner W, Horn P, Castoldi M, et al. Replicative senescence of mesenchymal stem cells: A continuous and organized process. PLOS One. 2008;3:e2213.

5. Choo KB, Tai L, Hymavathee KS, et al. Oxidative stress-induced premature senescence in Wharton's jelly-derived mesenchymal stem cells. Int J Med Sci. 2014;11:1201-1207.

6. Estrada JC, Torres Y, Benguria A, et al. Human mesenchymal stem cell-replicative senescence and oxidative stress are closely linked to aneuploidy. Cell Death Dis. 2013;4:e691.

7. Bonab MM, Alimoghaddam K, Talebian F, Ghaffari SH, Ghavamzadeh A, Nikbin B. Aging of mesenchymal stem cell in vitro. BMC Cell Biol. 2006;7:14

8. Kasper G, Mao L, Geissler S, et al. Insights into mesenchymal stem cell aging: Involvement of antioxidant defense and actin cytoskeleton. Stem Cells. 2009;27:1288-1297.

9. Nauta AJ, Fibbe WE: Immunomodulatory properties of mesenchymal stromal cells. Blood. 2007;110:3499-3506.

10. Krampera M, Cosmi L, Angeli R, et al. Role for interferon-gamma in the immunomodulatory activity of human bone marrow mesenchymal stem cells. Stem Cells. 2006;24:386-398.

11. Croitoru-Lamoury J, Lamoury FM, Caristo M, et al. Interferon-gamma regulates the proliferation and differentiation of mesenchymal stem cells via activation of indoleamine 2,3 dioxygenase (ido). PLoS One. 2011;6:e14698.

12. Ren G, Zhao X, Zhang L, et al. Inflammatory cytokine-induced intercellular adhesion molecule- 1 and vascular cell adhesion molecule-1 in mesenchymal stem cells are critical for immunosuppression. J Immunol. 2010;184:2321-2328.

13. Ren G, Zhang L, Zhao X, et al. Mesenchymal stem cell-mediated immunosuppression occurs via concerted action of chemokines and nitric oxide. Cell Stem Cell. 2008;2:141-150.

14. Braumuller $\mathrm{H}$, Wieder $\mathrm{T}$, Brenner $\mathrm{E}$, et al. T-helper-1-cell cytokines drive cancer into senescence. Nature. 2013;494:361-365.
15. Wang $S$, Zhou M, Lin F, et al. Interferon-gamma induces senescence in normal human melanocytes. PLoS One. 2014;9:e93232.

16. Kim KS, Kang KW, Seu YB, Baek SH, Kim JR. Interferon-gamma induces cellular senescence through p53-dependent DNA damage signaling in human endothelial cells. Mech Ageing Dev. 2009;130:179-188.

17. Chen K, Wang D, Du WT, et al. Human umbilical cord mesenchymal stem cells huc-mscs exert immunosuppressive activities through a pge2-dependent mechanism. Clin Immunol. 2010;135:448-458.

18. Aggarwal S, Pittenger MF. Human mesenchymal stem cells modulate allogeneic immune cell responses. Blood. 2005;105:1815-1822.

19. Watanabe Y, Suzuki O, Haruyama T, Akaike T. Interferon-gamma induces reactive oxygen species and endoplasmic reticulum stress at the hepatic apoptosis. J Cell Biochem. 2003;89:244-253.

20. Weyemi U, Lagente-Chevallier O, Boufraqech $\mathrm{M}$, et al. Ros-generating nadph oxidase nox4 is a critical mediator in oncogenic h-rasinduced DNA damage and subsequent senescence. Oncogene. 2012;31:1117-1129.

21. Coppe JP, Patil CK, Rodier F, et al. Senescence-associated secretory phenotypes reveal cell-nonautonomous functions of oncogenic ras and the p53 tumor suppressor. PLoS Biol. 2008;6:2853-2868.

22. Chien Y, Scuoppo C, Wang X, et al. Control of the senescence-associated secretory phenotype by nf-kappab promotes senescence and enhances chemosensitivity. Genes Dev. 2011;25:2125-2136.

23. Coppe JP, Patil CK, Rodier F, et al. A human-like senescence-associated secretory phenotype is conserved in mouse cells dependent on physiological oxygen. PLoS One. 2010;5:e9188.

24. Chomarat P, Banchereau J, Davoust J, Palucka AK. IL-6 switches the differentiation of monocytes from dendritic cells to macrophages. Nat Immunol. 2000;1:510-514.

25. Ritzman AM, Hughes-Hanks JM, Blaho VA, Wax LE, Mitchell WJ, Brown CR. The chemokine receptor cxcr2 ligand kc (cxcl1) mediates neutrophil recruitment and is critical for development of experimental lyme arthritis and carditis. Infect Immun. 2010;78:4593-4600.

26. Dhawan $\mathrm{P}$, Richmond $\mathrm{A}$. Role of $\mathrm{cxcl} 1$ in tumorigenesis of melanoma. J Leukoc Biol. 2002;72:9-18. 